\title{
Leprosy: An unusual presentation
}

\section{Geeta Kiran Arakkal, Sudha Vani', Harish Kumar Kasetty, Sirisha Varala ${ }^{1}$}

Department of DVL, Gandhi Hospital, 'Department of DVL, Gandhi Medical College, Hyderabad, Telangana, India

Address for the Correspondence: Dr. Geeta Kiran Arakkal, House No. 2, Vayupuri, Sainikpuri, Secunderabad, Telanagana, India. E-mail: geetakiran.a@gmail.com

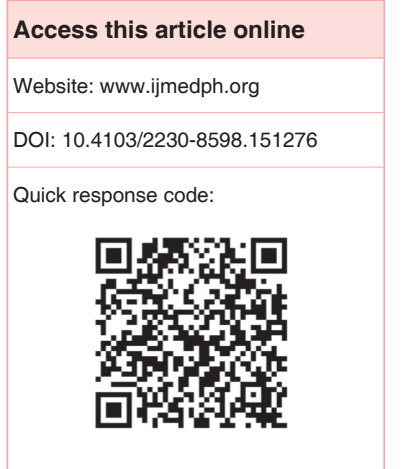

Leprosy is a chronic infectious disease caused by Mycobacterium leprae, commonly manifesting as hypopigmented anesthetic patches with thickened nerves. Primary hyperpigmentation in leprosy is a rare manifestation. Literature search showed only few case reports of Hansen's disease with single hyperpigmented patch and involvement of relatively immune zones like palms and soles. We report a case of leprosy presenting primarily as hyperpigmented patches over the trunk and extremities with involvement of palms and soles which is a rare presentation.

Key words: Hyperpigmented patches, leprosy, palms and soles, trunk

\section{INTRODUCTION}

Leprosy also known as Hansen's disease caused by the bacillus Mycobacterium leprae is a chronic infectious disease with various epidemiological characteristics and clinical manifestations. Leprosy predominantly affects the skin and peripheral nerves since $M$. leprae prefers cooler temperature of $<37^{\circ} \mathrm{C}^{[1]}$ Hypopigmented anesthetic patch with thickened nerve is a cardinal sign of leprosy. Although the secondary pigmentation due to clofazimine and lepra reaction is common, primary hyperpigmentation in leprosy is a rare feature.

There are certain immune zones like scalp, eyelids, axillae, palms and soles, lumbosacral area, midline back, groins and genitalia where leprosy lesions are rarely seen. ${ }^{[2]}$ But clinical, histological and bacteriological evidence of involvement of these so called "immune zones" have been documented. Hence, these zones are termed relatively immune rather than absolutely immune zones of leprosy. ${ }^{[3]}$

Literature search shows that very few cases with hyperpigmented patches in leprosy have been reported so far. Though many different manifestations of leprosy are known, not many reports of atypical and unusual presentations of the disease. We report a case of borderline tuberculoid (BT) leprosy manifesting as hyperpigmented patches over the trunk and extremities along with the involvement of palms and soles, which is a rare presentation.

\section{CASE REPORT}

A 44-year-old female presented to our department with tingling and numbness of hands and feet along with dark patches over the face, trunk and extremities of 20 days duration. There was no history of fever and any usage of topical or systemic medication.

Cutaneous examination revealed multiple, large, ill-defined hyperpigmented patches over the trunk, extremities, palms and soles [Figures 1-3]. There was reduced temperature, touch and pain sensation over the patches. Bilateral ulnar, radial cutaneous and lateral popliteal nerves were enlarged and nontender. A clinical diagnosis of BT leprosy with unusual involvement of palms and soles was made.

Routine investigations were within normal limits. X-ray chest was normal. Ultrasound abdomen revealed cholelithiasis and hemangioma of the right lobe of the liver. HIV, HbsAg and venereal disease research laboratory were negative. Bacteriological index and morphological index were also negative.

Skin biopsy from the lesions over the trunk and palm showed epidermal atrophy and increased melanin pigmentation of the basal layer [Figure 4]. Well-defined granulomas showing epithelioid cells, langhans giant cells and lymphocytes were seen in the dermis [Figure 5]. There was lymphocytic infiltration around the adnexa [Figure 6]. Melanin incontinence in the upper-dermis was seen. Bleaching with 


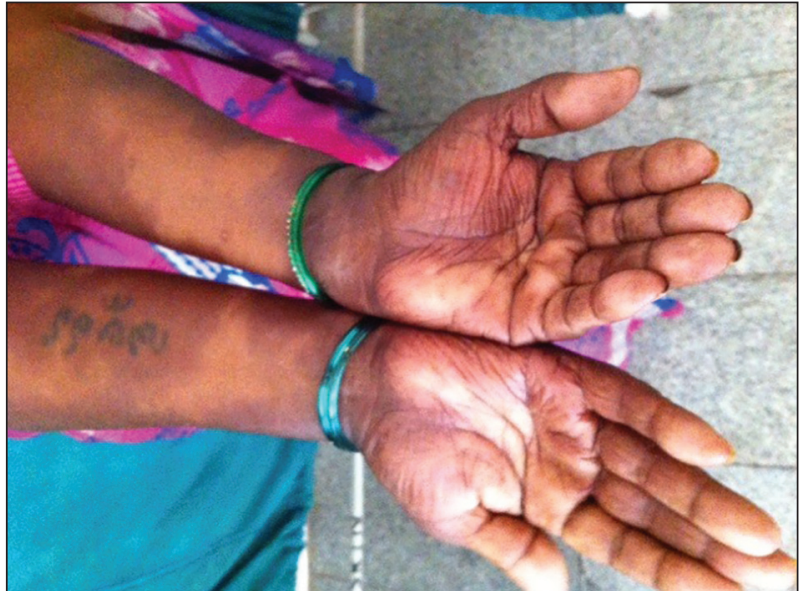

Figure 1: Hyperpigmented macules and patches over the palms and soles and over ther forearms

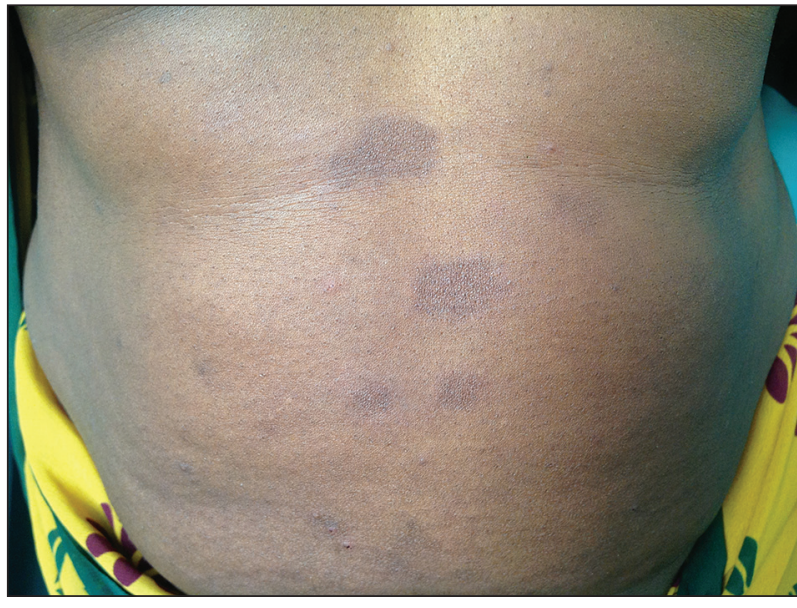

Figure 3: Hyperpigmented macules over the abdomen

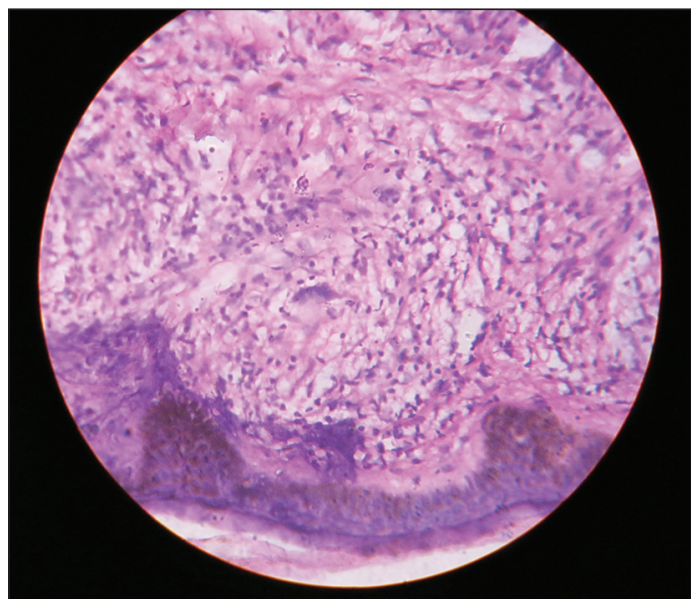

Figure 5: High power view (40x) showing increased pigmentation in the basal layer along with epitheloid granulomas and langhans giant cells in the dermis

potassium permanganate was done to confirm the presence of melanin. There was no evidence of any lepra reaction. Fite-faraco staining did not reveal lepra bacilli.

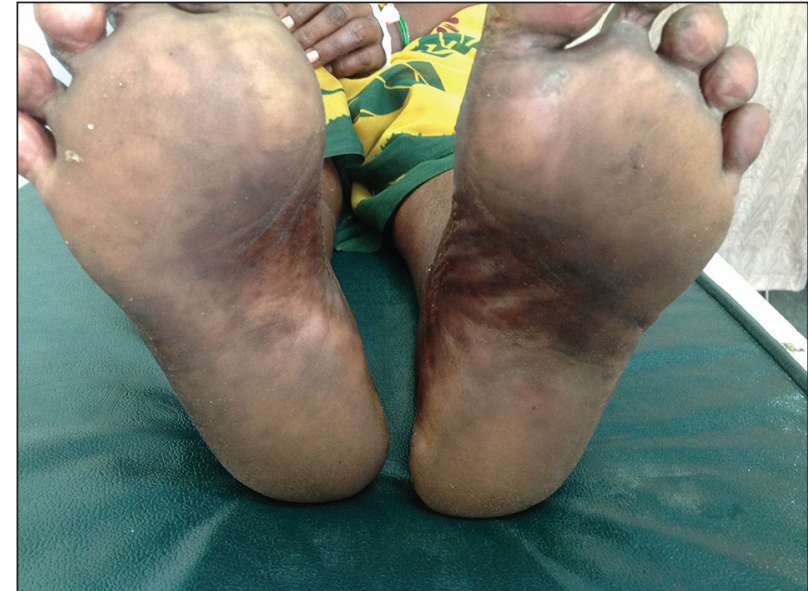

Figure 2: Hyperpigmented patches over the soles

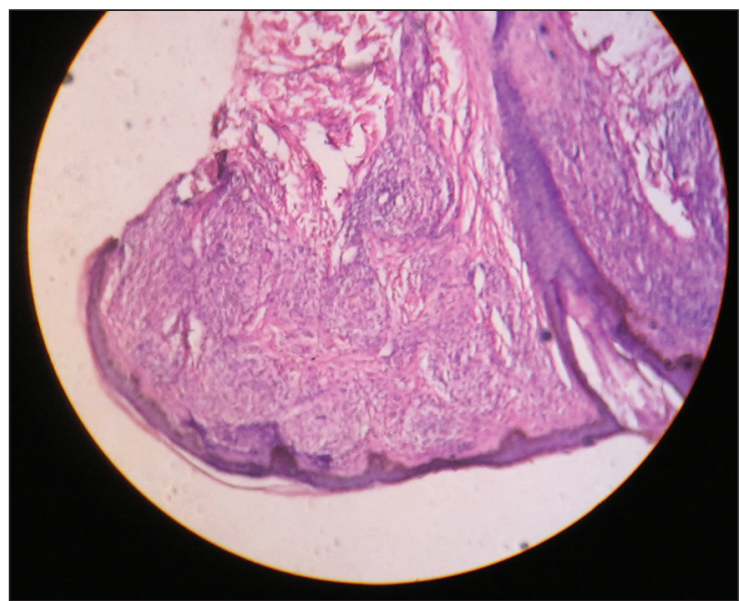

Figure 4: Scanner view (4x) showing epidermal atrophy and increased pigmentation in the basal layer and well-defined granulomas in the dermis

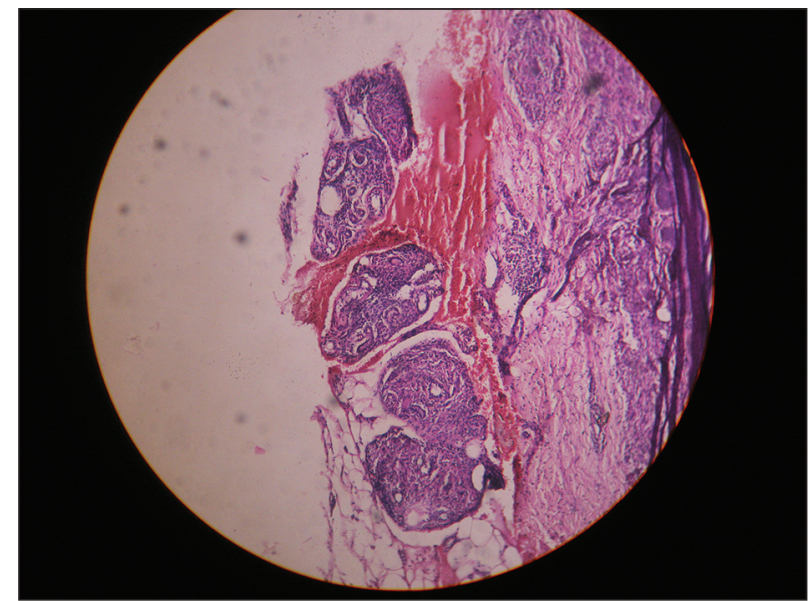

Figure 6: Scanner view $(4 \times)$ showing lymphocytic infiltrate around the adnexae

A diagnosis of BT Hansen's was confirmed, and the patient was started on multibacillary multi drug therapy and is under follow-up. 


\section{DISCUSSION}

Leprosy cases often present with classical features of hypopigmented anesthetic patches, thickened nerves and presence of acid-fast bacilli on slit-skin smear examination and skin biopsy. However, cases are also seen with atypical and uncommon manifestations. Primary hyperpigmentation in leprosy is a rare manifestation though the secondary pigmentation due to clofazimine therapy and lepra reaction is common.

A literature search revealed two case reports by Chattopadhyay and Gupta ${ }^{[4]}$ where Hansen's disease presented as hyperpigmented anesthetic patch on the pinna of the ear and another case with lumbosacral involvement. Mehta ${ }^{[5]}$ reported a case of tuberculoid leprosy with pigmented patches on the right leg. Okhandiar et al. ${ }^{[6]}$ reported two cases of tuberculoid and BT leprosy with hyperpigmented border. Grover et al. ${ }^{[7]}$ have reported a case of Hansen's disease presenting as hyperpigmented patches over the palms.

Our case showed hyperpigmented patches over the trunk, extremities, palms and soles unlike the earlier reports. Histology revealed increased pigmentation in the basal layer with evidence of BT leprosy.

Literature survey did not reveal any explanation for hyperpigmentation in leprosy. Hypothesis by Chattopadhyay and Gupta states that hyperpigmentation in leprosy may be due to the overactivity of melanocytes as a result of neurohormonal or biochemical stimulation. ${ }^{[4]}$

Though the exact mechanism of primary hyperpigmentation in leprosy is not clear, we believe that upregulation of melanogenic stimulating factors like fibroblast growth factor, hepatocyte growth factor and stem cell factors could possibly be responsible for the primary hyperpigmentation in leprosy.

Leprosy has a predilection for cooler and trauma prone areas of the body. ${ }^{[8]}$ Even though palms and soles are cooler, have a rich nerve supply and are more frequently prone to trauma, they are infrequently affected. ${ }^{[8]}$ This is mainly attributed to the thicker epidermis and fibro-fatty tissue of the palms and soles which results in a high nerve bed temperature. ${ }^{[8]}$

Palmoplantar lesions have been described by several workers in all forms of Hansen's disease. Indira et al. ${ }^{[8]}$ screened 280 patients of leprosy and found the palmoplantar involvement in 10\% of the cases. Lesions occurred more frequently in borderline leprosy than in lepromatous leprosy. ${ }^{[8]}$ Hopkins et al..$^{[9]}$ screened 245 patients of leprosy and found palmar involvement in $6.9 \%$ of cases and plantar involvement in $5.9 \%$ of the cases.

The incidence of palmoplantar lesions in reactions is reported to be high as shown by Arora et al. ${ }^{[10]}$ who found $50 \%$ of the patients with palmoplantar lesions to be in type 1 reaction.

Unlike Grover et al. ${ }^{[7]}$ who reported a case of BT leprosy with hyperpigmented lesions over palms and Chattopadhyay and Gupta $^{[4]}$ who reported two cases of tuberculoid leprosy, one with hyperpigmented anesthetic patch on the pinna of the ear and another case with lumbosacral involvement, our case presented as hyperpigmented patches over the trunk and extremities along with palmoplantar involvement which was never reported in literature.

Though leprosy has been declared to be eradicated in India, newer atypical and uncommon presentations are being reported. We present this case because of the atypical presentation of lesions in this patient. Hence, a high index of suspicion is necessary to diagnose unusual presentations of leprosy with hyperpigmented patches.

\section{ACKNOWLEDGMENTS}

Dr. Srivani, Department of Pathology, Gandhi Medical College, Hyderabad, Telangana, India.

\section{REFERENCES}

1. Hastings RC. The microbiology of leprosy. In: Leprosy. $1^{\text {st }}$ ed. Edinburgh: Churchill Livingstone; 1985. p. 37.

2. Jopling WH, McDougall AC. The disease. In: Handbook of Leprosy. $5^{\text {th }}$ ed. New Delhi: CBS Publications; 1996. p. 10-49.

3. Rajashekar TS, Singh G, Naik LC. Immune zones in leprosy. Indian J Dermatol 2009;54:206-10.

4. Chattopadhyay SP, Gupta CM. Primary hyperpigmented cutaneous lesions in tuberculoid leprosy. Indian J Lepr 1988;60:63-5.

5. Mehta VR. The primarily pigmented tuberculoid leprosy. Proceeding XII International Leprosy Congress. Vol. 1. 1984. p. 20.

6. Okhandiar RP, Sinha E, Sinha RK. Leprous lesion with hyperpigmented border. Indian J Lepr 1985;57:640-3.

7. Grover S, Singh G, Dash K. Primary hyperpigmented palmar lesion: A rare presentation of borderline tuberculoid leprosy. Indian J Lepr 1997;69:191-3.

8. Indira D, Kaur I, Sharma VK, Das A. Palmoplantar lesions in leprosy. Indian J Lepr 1999;71:167-72.

9. Hopkins R, Denney OE, Johansen FA. Immunity of certain anatomic regions from lesions of skin leprosy. Arch Dermatol 1929;20:767-79.

10. Arora SK, Mukhija RD, Mohan L, Girdhar M, Sharma SP. A study of palmoplantar lesions in leprosy: A preliminary report. Indian J Lepr 1989;61:206-8.

How to cite this article: Arakkal GK, Vani S, Kasetty HK, Varala S. Leprosy: An unusual presentation. Int J Med Public Health 2015;5:118-20.

Source of Support: Nil, Conflict of Interest: None declared. 